\title{
Luigi Pasinetti and the Political Economy of Growth and Distribution
}

\author{
Joseph Halevi ${ }^{1}$
}

Working Paper No. 40

April 2016

\begin{abstract}
Luigi Pasinetti's work has deeply affected modern economic theory. His papers on the Cambridge Capital Controversy are world renowned. But he has made many other contributions to the economic debates of the last half century, offering not only detailed criticisms of mainstream economic theory, but also the elaboration of an alternative, more complete, and coherent framework for understanding growth and income distribution, structural change, and trade relations. He has also made notable contributions to discussions of economic policy. Pasinetti's papers are very clearly written, but many are formidably technical and often build cumulatively on his previous work. This paper provides a careful and synthetic overview of his contributions as well as a reconstruction of Pasinetti's philosophical approach to economics as a science meant to serve humanity.
\end{abstract}

\footnotetext{
${ }^{1}$ Joseph Halevi is Professor Emeritus in the Department of Political Economy at the University of Sydney and a member of the faculty of the International University College of Turin. josephhalevi53@gmail.com.

This paper arises from a set of notes I wrote in July 2014 for Thomas Ferguson, the Research Director of the Institute for New Economic Thinking in New York, as he prepared for a series of meetings with Professor Luigi Pasinetti in Milan. Both he and Professor Geoffrey Harcourt strongly encouraged me to expand these. In the present paper the sequence is kept as in the original notes with some important additions while the text has been changed into a more discursive style.
} 
Key words: Luigi Pasinetti, Capital Controversy, Piero Sraffa, Classical Economics, Vertical Integration, Theory of Value and Prices, Structural Dynamics, Trade, Growth, Crises, Maastricht Criteria.

JEL codes: B31, B4, B5, C6, E1, F1 
Luigi Pasinetti's writings express - in a most consistent way from 1958 to the present - two interrelated features: extreme clarity and the fact that the philosophical, historical, and societal implications of his works emerge rather straightforwardly from the analytical framework contained in them. This aspect will be singled out as I proceed through his contributions. For the purpose of this paper I will divide Pasinetti's works into a number of stages. This is done essentially for analytical simplicity since the stages are themselves integrated with each other. For instance, the 1980s and most of the 1990s are dominated by his theory of vertically integrated processes and structural change (Pasinetti 1981, 1993). By contrast the 1960s appear to be characterized more by his publications on Ricardo's theory of capital accumulation (Pasinetti 1960); on debates over capital theory and the neoclassical rate of return (Pasinetti 1966, 1969); as well as on his seminal completion of Kaldor's Post-Keynesian theory of income distribution and growth culminating in the Cambridge equation (Pasinetti 1962, in Pasinetti 1974, Ch.V). However by 1965 Pasinetti had already presented the first draft of his novel approach based on vertically integrated sectors. Furthermore his preoccupation with dynamic processes related to the growth of productivity - the main objective of the vertically integrated approach - dates back to the late 1950s when, in a debate with Robert Solow, he came to the conclusion that the Solow type production function cannot account in any theoretically significant way for technical progress (Pasinetti 1965, 1959).

I will call the first stage the Cambridge-Sraffa phase, setting the cut-off point with the publication of the 1981 book Structural Change and Economic Growth. This period can be divided in two sub-phases: the Ricardo-Cambridge-Kaldor sub-phase and the Sraffa sub-phase. The last section of this survey will be devoted to Pasinetti's theoretical treatment of issues related to two ongoing crises: the European one and the global financial one.

\section{The Cambridge-Sraffa stage}

In the Ricardo-Cambridge-Kaldor sub-phase the essential text is Pasinetti's volume Essays on Growth and Income Distribution (1974) which includes, among other chapters especially written for that volume, the 1960 essay on Ricardo, the 1962 one on Kaldor's theory of income distribution and growth, as well as a very relevant critique of trade cycle models grafted onto a growth trend published in 1960. This latter showed that no trend factor can be consistently obtained from multiplier-accelerator cyclical models (Pasinetti 1974, ch. 
III). Pasinetti developed this view in a criticism of Duesenberry who attempted to do just that. The idea that cycles and growth could not be combined was also developed by Kalecki but in a much more cumbersome way than Pasinetti, since Kalecki did attempt to bring the two elements together but eventually gave up.

The 1960 paper on Ricardo lucidly showed that the latter's theory contains a logically consistent process of accumulation and growth leading eventually to a stationary state. The analytical foundations of such a dynamics lie in the Classical view that savings are made only for investment purposes, that wages are at subsistence so that the rate of profits is thereby determined as a residual, and that the diminishing fertility of each additional plot of land does not impact upon prices but affects, instead, the distribution of income of rents relative to the share and rate of profits. Pasinetti then goes on to show that Keynesian dynamics is distinct from Classical dynamics where wages are fixed at subsistence (Ricardo) or gravitate around subsistence (Marx). In Keynesian dynamics - from Harrod to Domar and, especially, in Kaldor - wages, not being at subsistence, emerge as a residual while the rate of profit is fixed first. In Keynesian dynamics the principle of effective demand, absent in the Classics, requires that wages grow at the same rate as productivity: were they to grow less the system would relapse into a state of Keynesian unemployment (Pasinetti 1974a).

In analyzing Keynesian dynamics Pasinetti established the general validity of the KaldorCambridge equation where what matters is the saving propensity out of profit (sp) even with a positive saving propensity out of wages (sw), provided the latter is LESS than the propensity to save out of profit. One of the main implications of the result consists in that without the condition $\mathrm{sp}>\mathrm{sw}$, a capitalist economy would not be able to function since the agents of capital accumulation (the capitalists) would eventually disappear. The robustness of the Cambridge equation is confirmed also by considering the case when wage earners save and receive interest. Yet when this is taken into account it cancels out, the crucial link being that between the growth rate and the propensity to save out of profits (Pasinetti 1974b). The outcome of the Pasinetti theorem is relevant in relation to the Piketty debate (Piketty 2014). In a capitalist economy the rate of profit will have to be always greater than the growth rate even under a more or less fair or stable distribution of income and wealth. A related implication concerns the importance that is to be assigned to stockholders' financial values: 
Very little. The crucial factor in ensuring capital accumulation is the reinvestment of profits not the distribution of dividends to stock owners (Pasinetti 2012).

In Pasinetti's works on growth, distribution and, later, on structural change, Keynes's principle of effective demand plays a crucial role because the evolution of the capitalist system has led to a state where profits no longer have to be residually determined. In building up the importance of Keynes's principle, Pasinetti shows that it stands independently from the theory of liquidity preference thereby driving a big wedge into the Hicks-Modigliani textbook version of Keynesian economics. It is shown that the principle is based on the distinction between actual production and productive capacity (Pasinetti 1974c) and this is what differentiates industrial from agrarian societies (notice how the historical divide between the two types of society emerges from the clear analytical approach that Pasinetti develops in order to explicate the principle of effective demand). In an agrarian society unsold fish and vegetables will rot, hence farmers will be tempted to get rid of the unsold produce, normally by reducing prices. By contrast in a modern economy if demand for industrial commodities declines there will be a downward adjustment in output and employment leading to unused productive capacity. The concept of productive capacity is central to Pasinetti's theory of growth and structural change published in 1981.

We now come to the Sraffa sub-phase, which overlaps in time with the Cambridge-Kaldor phase. The fundamental text here is Pasinetti's 1977 Lectures in the Theory of Production, published two years earlier in Italian (Pasinetti 1975, 1977).

Pasinetti's Lectures spell out fully the significance of Piero Sraffa's construction undertaken in his famous and slim book Production of Commodities by Means of Commodities published in 1960 simultaneously in Britain and in Italy. In Pasinetti's volume the relevance of the Sraffa system ranges from Leontief's input-output analysis - which in those years, while extensively used by international organizations, was being twisted towards a neoclassical factor substitution based framework, prompted by the influential neoclassical book of Dorfman, Samuelson, and Solow (1958) - to Marx's Labor Theory of Value and Neoclassical Capital Theory. At this point it may be more useful to proceed in a point-bypoint manner. 
(a) To begin with, Pasinetti shows that Leontief's and Sraffa's matrices are mutually consistent, one being the transpose of the other. This should cast doubts about the legitimacy of using the Leontief input-output system in a neoclassical fashion. In Sraffa's book and in Pasinetti's Lectures the price system emerges from the conditions of production, under the assumption of a uniform rate of profits, without any need to resort to supply and demand relations.

(b) Through an original elaboration of the Sraffa system, the Lectures show that the Classics, while grappling with a pure labor theory of value, were in fact gravitating towards a pure capital theory of value which obtains, in the limit, when the wage rate is zero so that the profit rate is at a maximum. It should be remembered that in Sraffa the full validation of the labor theory of value occurs, in a multi commodity framework, when commodities are produced by labor only.

(c) The Lectures show the consistency of Sraffa's Standard system where an invariable standard is obtained. This part may appear obscure, as it is an issue completely internal to the relationship between Sraffa and the Classics. However it is an important issue in regard to the Classical quest to separate values from distribution. The Lectures show that it is possible, through the standard commodity, to treat variations in distribution independently from changes in relative prices - which is what both Ricardo and Marx wanted to achieve via the labor theory of value. In fact, through the Standard system it is possible to abstract from different capital to labor ratios (in Marxian terms, from the different organic compositions of capital) prevailing in a multi-sector economy.

(d) By using a Sraffa type system the Lectures unlock the transformation problem in Marx. They prove that it is perfectly feasible to move from prices of production to labor values. What cannot be shown is which should come first, i.e. whether values arise from prices of production or vice-versa.

(e) The Neoclassical reaction to Sraffa's book was that its price system - free from demand and supply relations - depended on the special case of non-substitution or fixed coefficients of production. Pasinetti shows that there are Neoclassical fixed 
coefficients models where prices arise from traditional conditions. A most important example comes from the Dorfman-Samuelson-Solow (DOSSO) linear fixed coefficients neoclassical production model yielding radically different outcomes from Sraffa's theory. In the DOSSO case prices always emerge as scarcity indexes even though the DOSSO model is of a fixed coefficients kind. Thus, as Pasinetti points out, in a DOSSO model non-scarce commodities would have a zero price whereas in a Sraffa system non-scarce commodities have a positive price. It cannot, therefore, be argued that the Sraffa system is a special case of the neoclassical production model.

(f) Indeed, on the basis of the points (a) to (e), the Lectures show that it is the PAS system that is the special case (PAS = Paul Anthony Samuelson). The Neoclassical monotonic inverse relation between capital intensity and the rate of interest applies exclusively when there is only one sector in the economy. In general the principle of substitution is irrelevant.

(g) Point (f) is a negative result regarding the neoclassical theory of substitution. It was however already anticipated in the works that eventually became his 1981 Structural Change and Economic Growth, where a striking result was obtained in relation to the choice of techniques: variations in the wage rate do not matter in the choice of the methods of production, whereas variations in the rate of profits do, but the direction in which they impact upon the choice of the methods of production cannot be uniquely determined. This is a very important theoretical conclusion due to the conceptualization of production in terms of vertically integrated processes.

Pasinetti has provided the best and most lucid analysis of production systems. His treatment of capital in production models is particularly relevant today in the light of the renewed interest in the non-applicability of production functions extensively used to measure growth and factors' shares by organizations like the OECD, IMF, etc (Felipe and McCombie 2013).

\section{The vertical integration stage: from 1981 onward}

The first version of his approach, which Pasinetti elaborated in his Cambridge Ph.D. Thesis, was published in Vatican City in 1965. Afterwards the two main texts appeared. They are 
Structural Change and Economic Growth and Structural Economic Dynamics (Pasinetti 1981, 1993).

In both books the economy is described at a basic "natural" level, an idea also found in the Classics but which the Classics mixed, and confused, with actual states. Vertical integration is defined as a series of processes going back in the production of any given commodity. Hence each commodity occupies a certain slice of the economy. For instance a cell phone will absorb a certain slice of the aluminum, plastic, rare earth minerals, etc. It will also indirectly absorb a certain slice of the machinery used to mine rare earths, produce aluminum, etc., as well as a slice of the machinery needed to produce machinery. Since labor is assumed to be used in each and every process, each commodity can be expressed as a series of labor inputs (coefficients), while output is expressed in terms of units of productive capacity. The direct labor coefficients represent the labor input used to produce the final products, the indirect ones represent the labor going to produce the machinery (and its replacements) needed to produce the final product, while the hyper-indirect labor coefficients represent the labor inputs needed to produce new machinery net of replacement, that is capital accumulation. Each of these coefficients change (decline) because of technical progress. Prices are, in turn, determined in two ways. In a static way they are determined by the costs of production, but their changes depend on technical progress, that is on the decline of labor coefficients. Hence - and this is truly brilliant -- the dynamics of natural prices are determined by changes in the amount of labor needed to produce commodities. In a paper published a few years after his 1981 book, Pasinetti, by using the Sraffian concept of subsystems, proved that growing subsystems in a vertically integrated context allow for a generalization of the labor theory of value. More specifically he showed that to each quantity of a consumption good there corresponds a definite quantity of labor needed for its production (Pasinetti 1988).

Labor coefficients change at different rates from sector to sector. Hence the dynamic process is not uniform. Alongside labor coefficients there are per capita demand coefficients. They behave according to Engel type curves. Hence there is no symmetry between the dynamics of labor coefficients and those of per capita demand. Example: because of technical change labor coefficients in the bread industry will decline, but if Engel type behavior is assumed on 
the demand side, it is certain that the demand for bread won't rise enough to prevent a loss of jobs. The opening of new products to absorb the unemployed thus generated is a possibility but its occurrence on a scale that can prevent systemic unemployment is unsure. It will depend on two conditions discussed below.

The first is the effective demand condition: that is the condition whereby all the per capita demand coefficients together generate a level of effective demand which employs all the labor force for the production of what is being demanded. This condition is unlikely to be met by itself. The second condition is the capital accumulation condition. This is the dynamic condition for all the productive capacities to be utilized and capital to be added exactly in the proportions required to keep full employment. However by itself this condition may also not be satisfied if the effective demand condition is not satisfied as well. The full employment effective demand condition highlights theoretically that the problem of effective demand arises conceptually prior to the problem of capital accumulation. This line of reasoning is developed further in the 1993 book where all output is produced by labor only, hence there is no capital accumulation, and yet the problem of effective demand still arises.

In Pasinetti's framework the wage rate represents the connecting element in the system if it grows at the same rate as the average productivity rate. This is because it redistributes purchasing power throughout the economy through the dynamics of the coefficients of per capita demand. The wage rate, therefore, has an eminently macroeconomic meaning. With static wages evidently per capita demand cannot grow, hence the limited changes in some per capita demand coefficients must be offset by opposite changes in some other per capita demand coefficients. It must be pointed out, though, that even if wages were to operate efficiently by growing with average labor productivity, unemployment could still be possible. There is no guarantee that the rise in per capita demand for expanding products will create enough employment to absorb the redundancies arising from the declining sectors. Two observations follow. The first is that microeconomic efficiency does not entail macroeconomic efficiency. Pasinetti proves analytically what Keynes had rather casually stated in the General Theory of Employment Interest and Money. Namely, that while there is no reason to doubt entrepreneurs' ability to select their inputs appropriately, the failure to attain a full utilization of resources depends upon the system as a whole. Thus one should 
aim at a satisfactory, from an employment point of view, rather than at an optimal growth rate (Pasinetti 1987). The second observation is that it would be impossible to keep full employment over time without entrusting the task to a Central Agency.

In Pasinetti there is a continuous process of technical change but not a mechanism of factor substitution based, in the traditional sense, on changes in the relative prices of "factors" of production. There is no production function starting from initially given endowments. This is not an assumption, but an outcome of his vertically integrated approach and it may well be worthwhile spending few lines on the issue. A method of production is defined by the summation of the value of the direct, indirect, and hyper-indirect labor coefficients required to produce the final commodity. In this context the prices of capital goods are determined by the wage rate that multiplies the labor coefficients applied to the production of capital goods both for replacement and expansion as well as by the rate of profit that multiplies the proportion of capital goods that goes into the expansion of capital goods.

There is however a difference in the way in which the wage rate and the rate of profits contribute to the final prices of the means of production. As stated above the wage rate multiplies the labor coefficients of every single method of production and it therefore multiplies both the capital goods that are allocated for replacement and those produced for the net expansion of the stock of capital. The rate of profits by contrast enters into the price of capital goods via the annual amount of the lifetime of a machine produced for the net expansion of the stock of capital. Thus, if the life time of a new net machine is ten years, the rate of profits $\mathrm{c}$ - measured per annum - will multiply the annual amount of that machine, that is $1 / 10$, adjusted for the proportion of productive capacity of the machine going to the capital goods sector itself. It follows that while the wage rate can be factored out since it multiplies, through the labor coefficients, all the elements entering into the final price, the rate of profit cannot be taken out as it does not multiply all the said elements. If there are, say, three different methods of production A, B, C, the wage rate will multiply all of them equally. Their relative position will remain unchanged in the wake of variations of the wage. Changes in the wage rate are therefore immaterial to the choice of techniques. By contrast, this is not true for the rate of profit, because it does not equally multiply all the elements. Changes in it therefore will impact upon the relative position of each method of production. 
Yet we cannot say beforehand in which direction the choice of techniques will occur. This is a very important result that builds upon, but goes well beyond, the capital theory debates of the 1960s which culminated in the QJE symposium of 1966 with Pasinetti's crucial participation.

The analysis of the process of technical change and of the choice of techniques in the vertically integrated framework has important constructive implications. The capital theory debates of the 1960s reached a negative conclusion: the inverse monotonic relation between capital intensity and the rate of interest is an oddity. Nothing can be said beyond the observation that in general the relation will not hold. By contrast, in the Pasinetti framework the treatment of technical change and of the choice of techniques help us uncover important aspects of the economics of international trade and of development.

Pasinetti's approach has appeared to me to be most fruitful as it undermines completely traditional views about dualism and comparative advantages. We have seen that changes in the wage rate do not affect the choice of the technique of production. By the same token the methods of production used in a given country do not depend upon whether or not the wage rate is higher or lower relatively to that of other countries. This means that the Leontief paradox is no longer a paradox since what matters for the definition of capital intensity is not the capital/labor ratio - which defines the degree of mechanization - but the capital/output ratio, which defines the capital intensity of production. In this case an economy with a high level of labor productivity may well have a capital/output ratio lower, much lower, than less developed economies where labor productivity is significantly lower. Thus it is misleading to view trade as governed by relative factor endowments. It is rather determined by two principles: the principle of comparative productivity change advantage and its industry specific variant.

On the basis of the above considerations, the implications for the economy of export sectors are gauged on whether or not their productivity gains are leaked abroad, through lower prices for the consumers of the importing countries. If in a country the export sectors display a growth of productivity higher than that of the domestic non-tradable sectors by comparison with the same ratios in the importing country (say China is the exporting country and the USA is the importing one), then it can be said that China is leaking its productivity gains 
abroad. Thus the concentration of technical progress in the exporting sectors may not bring benefits to the domestic economy although, for the purpose of learning about new technologies, such a concentration may be initially necessary. By contrast, in a developed economy the technological differences between domestic and exporting sectors are not as big as in the less developed ones. Hence the developed economy's domestic sectors' productivity growth will roughly be the same as that of its own exporting sectors, so that the developed country is better able to retain productivity gains at home. This conclusion stems from the basic feature of Pasinetti's system where prices are determined by production costs so that their changes are governed by the dynamics of labor productivity throughout the whole chain of the vertically integrated labor coefficients. Pasinetti's point can be understood by looking at the issue from the angle of per-capita demand: the dynamics of per capita demand is linked to the dynamics of the wage rate which, in turn, is tied to the average growth rate of labor productivity. The wage rate is the element connecting the whole system, but if the largest part of it, i.e. the domestic sectors, displays a growth of productivity significantly below that of the exporting sectors, there would be little room to expand per capita demand. Hence, in the exporting country, dualism will set in because the importing countries will show a more even relation between productivity growth in the export and domestic sectors.

When applied to specific industries the principle of comparative productivity change advantage takes on a special dimension of practical relevance. When productivity growth in a particular exporting industry in a particular country, relative to the productivity growth in the rest of the economy in the same country, is greater than the same ratio in the rest of the world, then the competitive position of the exporting industry of the particular country will improve. In other words, if productivity growth in the Chinese auto industry relative to productivity growth of the Chinese economy is greater than the productivity growth of the auto industry in the rest of the world relative to productivity growth of the rest of the world economy, the international position of the Chinese auto industry will improve. If the dynamics of that ratio (auto industry productivity growth in China/China's productivity growth compared to auto industry productivity growth in the rest of the world/ rest of the world's productivity growth) is markedly favorable to China, the auto industry of the advanced countries (rest of the world) will find itself back in a position previously ascribed to infant industries. It will thus require protection in the same way as it was argued for the 
infant industries. Pasinetti calls this situation the mature industry case for protection. It should be noticed that Pasinetti wrote his theory - starting with his Cambridge University Thesis - when the phenomenon of massive industrial displacement arising out of industrial exports from much poorer countries was very limited. And yet he got the structural tendencies quite correctly.

Furthermore, it would be mistaken to conclude that when the ratio discussed in the foregoing paragraph is favorable to, say, China, the improvement in the international position of the Chinese auto industry will automatically benefit China. For this to happen it is necessary that, on the Chinese side, the ratio is improved by an expansion of the numerator, that is by an increase in the productivity growth of the auto industry relative to the productivity growth of the Chinese economy. If, instead, the expansion of the Chinese ratio relative to the same ratio in the rest of the world occurs because of a fall in the Chinese denominator then, the Chinese economy will not benefit, although the international position of its auto industry will. Conversely if the Chinese ratio falls compared to the rest of the world ratio because of a big rise in the Chinese denominator then too bad for the international status of the Chinese auto industry, but it is good news for China because it means that its overall productivity has expanded.

Luigi Pasinetti's treatment of international economic relations is compelling and it is powerful also at the didactic level due to the pristine clarity of the author's exposition. I have used Pasinetti's theory in my Masters course called China in the World Economy which I developed at the University of Sydney in 2004 in order to look more closely into the striking transformation of the People's Republic. The students found Pasinetti's approach to be an effective conceptual framework to navigate the evolution of the Chinese economy in its international dimensions. We also conducted comparisons with other economies like Mexico, Brazil, and India and we asked questions like why hasn't this kind of development happened to the same degree with Mexico or India or Brazil? Here too Pasinetti's approach is most illuminating. If one uses the vertically integrated labor coefficients approach to industrial production, it would not take long to understand what happens if VW managers were to say "in the Congo wages are so low that we are going to move there." Even assuming that local labor is perfectly malleable, for VW the outcome will be a disappointment. All the materials, 
machinery, transport equipment and related facilities will have to be imported from the EU and calculated according to EU costs of production. The end result will be that EU priced capital charges will figure in a very high proportion of the final production price of the Congo made VW where the only local inputs, the direct labor coefficients, are priced at the very low Congo wages. This means that the Congo made VW would not have a domestic demand basis. Moreover, the importation by VW of the machinery and transport equipment from Europe will show up as foreign capital inflows spent to pay for those imports. This may well leave the Congolese financial system saddled with an external debt while the economy is subjected to a steady flow of industrial imports. How much labor would Congo have to sacrifice in export activities in order to sustain the process? Given the high price of the imported goods from Europe by VW, it is possible that the amount of labor which will have to be sacrificed will end up being excessive relatively to domestic developmental needs. I will return on this issue in the next paragraph. Thus for a China type phenomenon to emerge it is necessary that there exist a domestic industrial structure capable of undertaking the transformation without its production costs being burdened with excessive capital charges arising from inputs and machinery imported from countries with much higher per capita incomes and, therefore, much higher production costs.

But how can a poor country avoid, or minimize, the risk of being burdened by too high capital charges from the richer countries? Traditional theory would tell us to this very day although things have been made more complicated with informational asymmetries, rent seeking activities, etc., the basic skeleton has remained the same - that the poor country would have to adopt production techniques based on those domestic factors that are more abundant, therefore cheaper. Capital - real - not being among them, the choice of technique should fall on labor intensive productions. We have seen however that in a proper system of production, of which the vertically integrated process is an expression, the relative wage rate is immaterial to the choice of techniques. Hence if a poor country has access to the most advanced methods of production - available, say, in Sweden - it should adopt them forthwith. For comparable production, the best method in Sweden is also the best method in Papua New Guinea. Yet the gap in the wage levels between the two countries is such that were Papua New Guinea to import the methods from Sweden it would find itself burdened by the high level of capital charges in its final prices. The answer is that the poor country 
should weigh against the importation of the most advanced methods of production the amount of labor it has to surrender abroad in order to pay for the imported technologies relative to the amount of labor it will have to lock into less efficient home produced methods. The amount of labor surrendered abroad is simply the labor needed to produce the goods which have to be exported. If this amount exceeds the labor required to produce home-made technologies and capital goods then it will pay to refrain from buying the most advanced methods from abroad. The conclusion to which Pasinetti's theory brings us in relation to the selection of technologies in an underdeveloped country converges towards similar considerations raised in the development planning literature of the 1950s and 1960s especially in Cambridge and in India (Dobb 1960; Sen 1960). However a significant difference exists between the earlier literature and Pasinetti's theory. In the Dobb-Sen models priority was supposed to be given to the capital goods sector and that was it. Just about nothing could be said about the status of consumptions goods and, more importantly, about the status of those who were supposed to consume the goods.

The vertically integrated theory of Luigi Pasinetti is based on a multiplicity of consumption goods the demand for which follows an Engel type pattern. To each consumption good a capital goods sector is attached, producing a machine for itself and for the consumption goods sector. It follows that investment priority in the capital goods industry does not make much sense unless further specified. It is the developmental priority in a set of consumption goods that will entail an investment priority in the corresponding, indeed attached, set of capital goods. How should the set of consumption goods be selected? In Pasinetti per capita demand coefficients are not randomly listed. They are arranged according to a hierarchical order not dissimilar to Engel's characterization. Thus priority should be given to those commodities where demand should grow most. If, say, in a country the main issue is to change nutritional patterns, investment should go into those sectors providing the machinery and technologies needed to modify them. This may well mean that if agricultural equipment is lacking, and importing it is subject to the limitations described above, that machinery will have to be produced in the country which may require building the relevant steel plants, mechanical industries, etc. But if the program is to be completed successfully the agricultural sector should, for a while, absorb a large slice of the sectors directly and indirectly contributing to it. The hierarchical order in which consumption should be selected 
arises in Pasinetti as a theoretical necessity rooted in the social reality of mass poverty to this very day. It also expresses the philosophical humanism of Luigi Pasinetti, based on the centrality of labor, to which I will now turn.

The superiority of labor over capital is the overarching theme in the two Pasinetti books on structural change. The special role of labor stems from the fact that humanity's creative and productive activities require labor. Only the latter can make capital goods not the other way round. In a growing economic system the production of additional capital goods requires a rate of profit but this too arises from labor. In Pasinetti's natural economic system the rates of profit are determined by the growth rate of population and the growth of per capita demand for the commodities concerned. Since the growth of demand for each commodity is different, natural profit rates will differ as well. If population growth is zero, profit rates will be determined solely by the growth of demand for each commodity. Clearly this growth of demand is entirely determined by the growth rate of labor productivity. Thus the Pasinetti rate of profit is in fact determined by labor, that is by its growth and by its productivity. This view was already contained in the Cambridge-Kaldor phase of his writings. The 1974 book of essays on Growth and Income Distribution ends with a long chapter, chapter VI, dedicated to closing the debate over Kaldor's theory of growth and over the Pasinetti Theorem - where it is proven that long term equilibrium growth depends on the rate of profit multiplied by the saving propensity out of profits independently of everything else - which upon its publication elicited a neoclassical response from Franco Modigliani and Paul Samuelson. At the end of the chapter Pasinetti points out that in long term, growth, with all profits saved, the stock of capital disappears altogether from the fraction $(\mathrm{P} / \mathrm{K})$ defining the rate of profits. In other words, the rate of profit turns out to be independent of the stock of capital, being exclusively determined by the growth rate of population and of labor productivity (Pasinetti 1974b). Thus labor is the crucial factor for the formation of a rate of profit. Labor is also a crucial factor in the formation of the rate of interest in a manner that is totally independent from the rate of profits.

In his 1993 book Pasinetti showed how from even the simplest form of such a natural system, a situation where there is no accumulation and everything is produced by labor, a positive monetary rate of interest arises even with no rate of profits and hence with no accumulation 
of capital. The procedure is rather straightforward: it is enough to assume that while all output is consumed, some households will save, consume less than their total income, and some households will borrow to consume what savers have not. Then there will be a financial system with credits and debts and a rate of interest attached to the loans. This rate of interest arises totally independently of profits. The objective justification for charging an interest on loans resides in protecting the value of the loan during repayment. In Pasinetti's system, labor is the source of all productive activities and, as we have seen, also the natural rate of profits is determined by the growth of labor productivity. Preserving over time the value of loans/debts means therefore maintaining their purchasing power in terms of labor. If a loan is made at time $t(0)$ to be repaid at time $t(1)$, and if from $t(0)$ to $t(1)$ labor productivity increases by $\mathrm{z} \%$, the corresponding rate of interest, i.e. the rate of interest which will safeguard the purchasing power in terms of labor of the loans made at $t(0)$, will have to be equal to the growth rate of productivity z. This is what Pasinetti has called the natural rate of interest. That rate of interest happens, as he himself pointed out (Pasinetti 2002), to be consistent with the principle of equal exchange as no advantages are obtained by either borrowers or lenders. It will be noticed that both the (natural) rate of profits and (natural) the rate of interest are determined by labor through its productivity, although they arise for totally different reasons. The rate of profits emerges because of the production and utilization of capital goods, while the rate of interest may exist also in a zero profits economy provided there are individuals who save and individuals who borrow to consume more than their current income.

Chronologically, after Karl Marx, Luigi Pasinetti is the thinker that has most strongly put labor at the very center of economic activity. He has done it in a different philosophical framework which, in its own right, has vastly enriched our understanding of both theory and society.

\section{Pasinetti and the present crises.}

The conceptual consistency of Pasinetti's contributions has proven itself also in relation to the economic recession and stagnation which set in since 2008, as well as in relation to the quagmire in which the area of the European Union covered by the European Monetary Union (the Eurozone) finds itself. Let us begin with the European situation. 
Shortly after the signing of the Maastricht Treaty Pasinetti saw the problems arising from the Maastricht criteria of a 3\% government budget deficit and a $60 \%$ ceiling on the national debt. In the 1990s to that effect he gave seminars at the Bank of Italy. He defined the Maastricht criteria as being either a myth or a folly since there is no reason why a particular set of values should define the limit of the deficit and of the debt. Just the same he took a proactive position by putting forward an argument aimed at reducing the damage as much possible

In 1998 in a now famous Cambridge Journal of Economics paper he showed that debt stabilization as a criterion is a much preferable to straight convergence to Maastricht values. For countries with a high debt ratio the stabilization criterion would imply a much less restrictive budgetary policy (Pasinetti 1998). Countries would not be compelled to undertake drastic austerity measures which, as now amply proven, fail in their own terms, leading to higher debt levels. Alongside the CJE article Pasinetti also produced theoretical and empirical papers regarding the sustainability zone devising a method aimed at showing the burden of the debt (Pasinetti 1997). This is the amount of income that has to be given up as proportion of nominal GDP in order to service the debt. In fact Pasinetti developed two conditions:

(1) $t=(i-g) D / Y$, where $t$ is the burden of the Debt $D$ and $i$ and g are the interest and nominal growth rates respectively. $\mathrm{Y}$ is nominal GDP.

The second condition is a debt sustainability condition which is expressed as:

(2) $\mathrm{S} / \mathrm{Y} \geq-\mathrm{gD} / \mathrm{Y} \quad$ Where $\mathrm{S}$ is not savings but the government's surplus

On policy makers the impact of those contributions has been negligible because, from the start, in Europe, excluding the U.K., the discussion about the single currency has been taken out of the realm of rational discourse. We can now move to the present crisis.

In the press the crisis has often been linked, with good reasons, to the priority that the institutions of modern capitalist countries, at least those of the United States and of the United Kingdom, with the crucial participation of Swiss, French and German banks and the entire Spanish, Irish and Icelandic economies, have given to the inflation of the value of financial assets and to physical assets containing a dominant component of financial rents, such as real estate. The increasing importance that, over the last two to three decades, has been assigned to 
stockholders' values is a major factor in the priority given to asset price inflation. In this context Pasinetti has published recently in the Cambridge Journal of Economics an essay I have referred to at the beginning of this survey but only in a cursory manner (Pasinetti 2012).

In that paper it is pointed out that neoclassical theory when applied to financial matters such as the value of stocks and dividend policies obscures the objective role of capitalists' savings. Their main function is to sustain the accumulation of capital through investment. By contrast, says Pasinetti, neoclassical economics has come up with a number of constructions where the focus is not the maximization of profits through investment but the maximization, through the stock exchange, of corporate stock values. Pasinetti mentions explicitly the Modigliani-Miller theorem of the late 1950s noting that "the theorem has led to the belief that there is no difference between the two traditionally considered alternatives regarding the allocation of each single firm's profits, i.e. (i) that of using them internally by adding them to the existing capital stock, or (ii) that of immediately distributing the dividends to the shareholders" (Pasinetti 2012, p.1442). The belief arises from the, ideological, acceptance of perfect financial markets. The influence of both the Modigliani-Miller theorem and, I should add, of Fama's efficient market hypothesis, on financial institutions and on policy making bodies created an atmosphere conducive to economic irresponsibility with regard to corporations' use of their profits. It has also blinded the political institutions' view as to the requirements of real capital accumulation for the economy as a whole.

Pasinetti observes that in final analysis the stability or instability of the economy will be determined by whether or not the conditions for real capital accumulation are satisfied in relation to the conditions of full employment growth. This is precisely what is highlighted in the Pasinetti Theorem of 1962 (Pasinetti 1962, $1974 \mathrm{ch} \mathrm{V).} \mathrm{Without} \mathrm{the} \mathrm{saving} \mathrm{propensity} \mathrm{out}$ of profit being greater than the saving propensity out of wages, so that the latter is always smaller than the ratio of aggregate investment over national income $(\mathrm{sw}<\mathrm{I} / \mathrm{Y})$, the economy would not be in a position to function. The implications arising from the Kaldor-Pasinetti framework combined with the labor focused approach of the 1981 and 1993 contributions, are then contrasted with the Modigliani-Miller view. Financial securities, instruments and paper assets can be created ad infinitum without any physical limits. But capital goods cannot be produced beyond what is required for full employment growth. Were this to occur the 
economy would be quickly struck by the formation of unused capacity thereby leading to unemployment.

The crisis of 2008 and beyond was not caused an over-production of capital goods but the merit of the example lies in showing the boundaries within which the economy can operate and gauge whether financial companies' ability to generate unlimited instruments creates the illusion of being in an unbounded system, on the debt-credit side, with negative consequences for employment. 


\section{Bibliographical References}

\section{References to Pasinetti's Works}

Pasinetti, Luigi L. (1958) "Il recente modello di sviluppo di J. Robinson e la teoria neoclassica del capitale: alcune osservazioni Rivista Internazionale di Scienze Sociali, Vol.66, pp. 429-444.

Pasinetti, Luigi L. (1959) "On Concepts and Measures of Changes in Productivity," The Review of Economics and Statistics, vol. 41, pp. 270-282 [Reprinted in Pasinetti 1974, chapter I

Pasinetti, Luigi L (1960) "A Mathematical Formulation of the Ricardian System," The Review of Economic Studies, vol. 27, pp.78-98.

Pasinetti, Luigi L. (1960) "Cyclical Fluctuations and Economic Growth Oxford Economic Papers, New Series, Vol. 12, No. 2, pp. 215-241 [Reprinted in Pasinetti 1974, chapter III].

Pasinetti, Luigi L. (1962) "Rate of Profit and Income Distribution in relation to the Rate of Economic Growth The Review of Economic Studies, vol. 29, 267-279 [Reprinted in Pasinetti 1974, chapter V].

Pasinetti, Luigi L. (1965) "A New Theoretical Approach to the Problem of Economic Growth Vatican City: Pontificiae Academiae Scientiarum Scripta Varia, n. 28.

Pasinetti, Luigi L. (1966) "Changes in the Rate of Profit and Switches of Techniques," Quarterly Journal of Economics, vol. 80, pp. 503-517.

Pasinetti, Luigi L. (1969) "Switches of Techniques and 'the Rate of Return' in Capital Theory The Economic Journal, vol. 79, pp.508-531.

Pasinetti, Luigi L. (1974) Growth and Income Distribution - Essays in Economic Theory, Cambridge U.K.: Cambridge University Press. 
Pasinetti, Luigi L. (1974a) "From Classical to Keynesian economic dynamics in Pasinetti 1974, chapter IV, pp. 86-102.

Pasinetti Luigi L. (1974b) "The rate of profit in an expanding economy in Pasinetti 1974, chapter VI, pp. 121-146.

Pasinetti, Luigi L. (1974c) “The economics of effective demand in Pasinetti 1974, chapter II, pp. 29-53.

Pasinetti, Luigi L. (1975) Lezioni di teoria della produzione, Bologna: Il Mulino.

Pasinetti, Luigi L. (1977) Lectures on the Theory of Production, New York N.Y.: Columbia University Press.

Pasinetti, Luigi L. (1981) Structural Change and Economic Growth, Cambridge U.K.: Cambridge University Press.

Pasinetti, Luigi L (1987) “'Satisfactory' versus 'Optimal' Economic Growth Rivista internazionale di scienze economiche e commerciali, October, Vol. 34 (10), pp. 989-999.

Pasinetti, Luigi L. (1988) "Growing subsystems, vertically hyper-integrated sectors and the labour theory of value Cambridge Journal of Economics, Vol. 12 (1), pp. 125-134.

Pasinetti, Luigi L. (1993) Structural Economic Dynamics, Cambridge U.K.: Cambridge University Press.

Pasinetti, Luigi L (1997) “The Social 'Burden' of High Interest Rates” in: P. Arestis, G. Palma, and M. Sawyer (eds.), Capital Controversy, Post-Keynesian Economics and the History of Economic Thought, volume I; London \& N.Y: Routledge, pp. 161-168. 1997.

Pasinetti, Luigi L (1998) “The myth (or folly) of the 3\% deficit/GDP Maastricht 'parameter' Cambridge Journal of Economics, Vol. 22 (1), pp. 103-116.

Pasinetti, Luigi L (2002) “An «analytical» approach to the «just» rate of interest: the priority of labour over capital Rivista Internazionale di Scienze Sociali, Anno 110, No. 3 (LuglioSettembre), pp. 323-329. 
Pasinetti, Luigi L. (2012) "A few counter-factual hypotheses on the current economic crisis Cambridge Journal of Economics, vol. 36 (6), pp. 1433-1453.

\section{Other References}

Dobb, Maurice (1960) An Essay on Economic Growth and Planning, London: Routledge \& Kegan Paul.

Dorfman, Robert; Paul Samuelson, and Robert Solow (1958) Linear Programming and Economic Analysis, New York N.Y.: McGraw-Hill.

Felipe, Jesus and John S.L. McCombie (2013) The Aggregate Production Function and the Measurement of Technical Change : 'Not Even Wrong', Cheltenham: Edward Elgar.

Piketty, Thomas (2014) Capital in the Twenty-First Century, Cambridge, Massachusetts : The Belknap Press of Harvard University Press [originally published as Le capital au XXIe siècle, Paris: Seuil, 2013].

Sen, Amartya (1960) Choice of Techniques: An Aspect of the Theory of Planned Economic Development, Oxford: Blackwell.

Sraffa, Piero (1960) Production of Commodities by Means of Commodities, Cambridge: Cambridge University Press; and: Produzione di merci a mezzo di merci, Torino: Einaudi, 1960. 